\title{
Trust Model for Dependable File Exchange in Cloud Computing
}

\author{
El-Sayed M. Towfek El-kenawy \\ Department of Computer and Systems Engineering \\ Delta Higher Institute for Engineering \&Technology (DHIET)), Mansoura, Egypt
}

\begin{abstract}
Cloud computing has ended up being a suitable decision for giving registering and storing assets particularly for little and medium estimated organizations lately. The "pay per use" expense model, on interest processing, substantial scale stockpiling asset with simple access and liberating clients from overseeing and keeping up assets are among the essential variables that have settled on cloud an alluring decision for such administrations. The issue of low trust on distributed computing is an obstruction, one of the significant snag to its pervasive organization, especially if there should arise an occurrence of basic information storage on the suppliers datacenter. This paper displays a model for trust in cloud computing. Representing vital components which shape the clients trust and a method for assessing every component's significance
\end{abstract}

\section{Keywords}

Cloud Computing, Service, Trust, Cloud Computing, File system, Integrity, Reputation, Security and Trust

\section{INTRODUCTION}

Cloud computing is presented as one of the most sultry and most encouraging issues in Information and Communication Technology (ICT), However, the absence of trust in distributed computing is keeping it from being utilized generally among clients. Having distinctive definitions in figuring writing "trust" is considered as followed in this paper: the eagerness of a gathering to be helpless against the activity of another gathering in view of the desire that the other will perform a specific activity essential to the trust or, independent to the capacity to screen or control that other gathering". To utilize distributed computing utilities, clients need to place their assets (information, applications) in the cloud supplier's datacenter. Since clients don't have direct control over their documents on cloud supplier's datacenter, the trust assessment would be a basic issue for them. Since conceivable dangers would debilitate cloud assets, the requirement for trust emerges as an imperative consider particularly indispensable information and exchange preparing applications. To address clients concerns, cloud suppliers need to devise systems to wipe out these dangers. Raising the significance of trust, as of late "oust as an administration" is risen to cloud plan of action in which the trust may be offered at distinctive levels with diverse costs so higher trust level would be accomplished at a higher expense.

\section{CLOUD COMPUTING}

Cloud computing alludes to the utilization, through the Internet, of assorted applications as though they were introduced in the client's PC, freely of stage and area. A few formal definitions for distributed computing have been proposed by industry and the educated community. We receive the accompanying definition: "Distributed computing is a model for empowering helpful, on-interest system access to a common pool of configurable processing assets (e.g., systems, servers, stockpiling, applications, and administrations) that can be quickly provisioned and discharged with negligible administration exertion or administration supplier association". This definition incorporates cloud architectures, security, and sending methods.

Cloud computing is in effect logically received in distinctive business situations so as to get adaptable and solid registering situations, with a few supporting arrangements accessible in $t$ business. Being taking into account differing advancements (e.g. visualization, utility registering, network figuring and administration arranged architectures) and constituting an entire new computational ideal model, distributed computing obliges abnormal state administration schedules. Such administration exercises include: (an) administration supplier determination; (b) virtualization innovation choice; (c) virtual assets portion; (d) observing and evaluating to ensure Service Level Agreements (SLA). Computational trust can be utilized keeping in mind the end goal to set up construction modeling and an observing framework including everything these needs and as yet supporting normal exercises, for example, arranging,,, provisioning, adaptability and security. Chang et al. presents a couple difficulties identified with, security, execution and accessibility in the cloud.

\subsection{Cloud Computing Structural design}

The cloud computing architecture modeling is taking into account layers. Every layer manages a specific part of making application assets accessible. Fundamentally there are two fundamental layers: a lower and a higher asset layer. The lower layer includes the physical framework and is In charge of the virtualization of capacity and computational assets. The higher layer gives particular administrations. These layers may have their own administration and checking framework, free of one another, hence enhancing adaptability, reuse and versatility. Figure 1 displays the distributed computing design layers. 


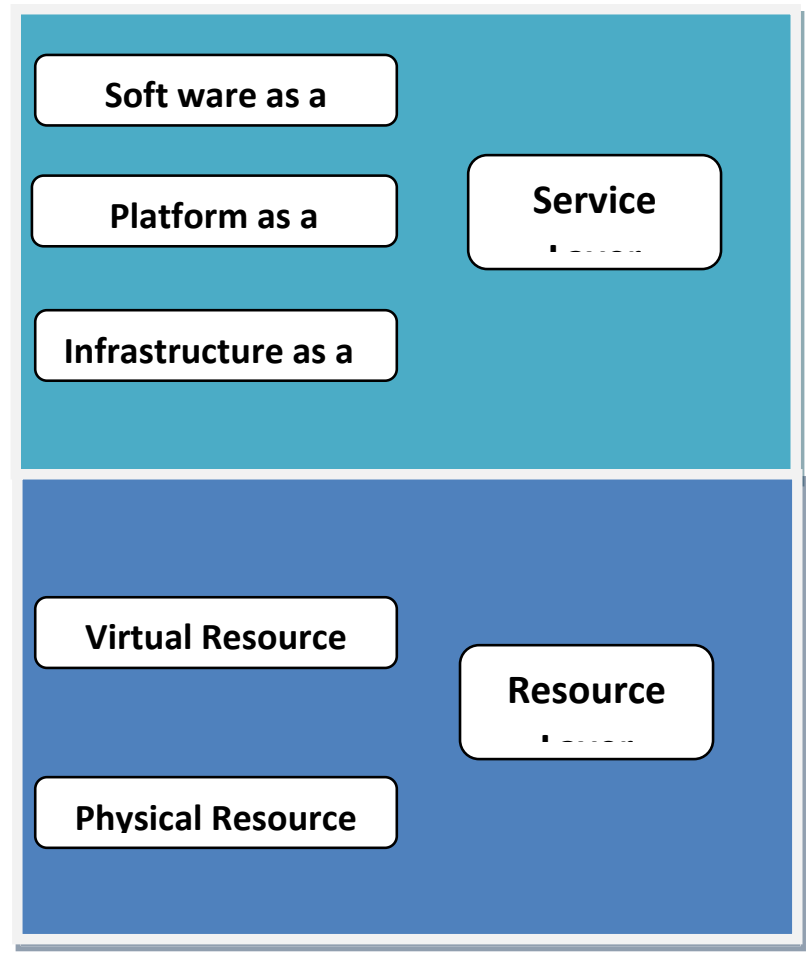

Figure 1: Cloud Computing Architectural Layer

\subsection{Software as a Service}

Software as a Service (SaaS) gives all the elements of a conventional application, however gives access to particular applications through Internet. The SaaS model diminishes concerns application servers. Working frameworks, stockpiling, and application advancement, and so on. Henceforth, designers may concentrate on foundation, prompting speedier programming frameworks Improvement. SaaS frameworks diminish costs since no product licenses are obliged to get to the applications. Rather, clients access benefits on interest. Since the product is basically Web based, SaaS permits better mix among the specialties units ofa given association or even among diverse programming administrations. Cases of SaaS include: Google 1 Docs and Customer Relationship Management (CRM) administrations.

\subsection{Platform as a Provision}

The Platform as a Service (PaaS) Is the center pan of the administration layer in the cloud. It offers clients programming and administrations that don't oblige downloads or establishments. PaaS furnishes a framework with an abnormal state of incorporation so as to execute and test cloud applications. The client does not deal with the framework (counting system, servers, working frameworks and capacity), yet he controls conveyed applications and, conceivably, their setups. PaaS gives a working framework, programming dialects and application programming situations. Hence, it empowers more effective programming frameworks execution, as it incorporates apparatuses for improvement and joint effort among designers. From a business outlook. PaaS permits clients to exploit outsider administrations ,expanding the utilization of bolster demonstrate in which clients subscribe to IT benefits or get issue determination guidelines through the Web. In such situations, the work and the obligations of organization IT groups can be better overseen. Cases of SaaS include: Azure Services Platform (Azure), Force.com, Engine Yard and Google App Engine.

\subsection{Infrastructure as a Facility}

Infrastructure as a Service (laaS) is the bit of the construction modeling in charge of giving framework important to PaaS and SaaS. Its primary target is to make assets, for example, servers, system and capacity all the more promptly open by including applications and working frameworks. Consequently, it offers fundamental foundation on-interest administrations. IaaS has a special interface for base administration, an Application Programming Interface (API) for connections with hosts,switches and switches, and the capacity of including new gear in a basic and straightforward way. When all is said in done the, client does not deal with the hidden equipment in the cloud framework, yet he controls the working frameworks, stockpiling and $\mathrm{S}$ conveyed applications.

In the long run he can likewise choosesystem segments, for example, firewalls. The term laaS alludes to a registering framework, in view of visualization procedures that can scale rapidly,expanding or lessening assets as indicated by the needs of utilizations. The primary advantage gave by laaS is the pay-per-use plan of action. Samples of laaS include: Amazon Elastic Cloud Computing (EC2) and Elastic utility Computing Architecture Linking Your Programs toSystems (Eucalyptus)

\subsection{Roles in Cloud Computing}

Role characterizes the obligations, access and profile of diverse clients that are a piece of a distributed computing arrangement. Figure 3 exhibits these pans characterized in the three administration layers. The supplier is in charge of overseeing, checking and ensuring the accessibility of the whole structure of the distributed computing arrangement. It liberates the designer and the last client from such obligations while giving administrations in the three layers of the construction modeling. Engineers utilize the assets gave by laaS and paas to give programming administrations to last clients. This multi-part association serves to characterize the performing artists (individuals who assume the parts) in distributed computing situations. Such ' on-screen characters may assume a few pans in the meantime as per need or hobby. Just the supplier underpins all the administration layers 


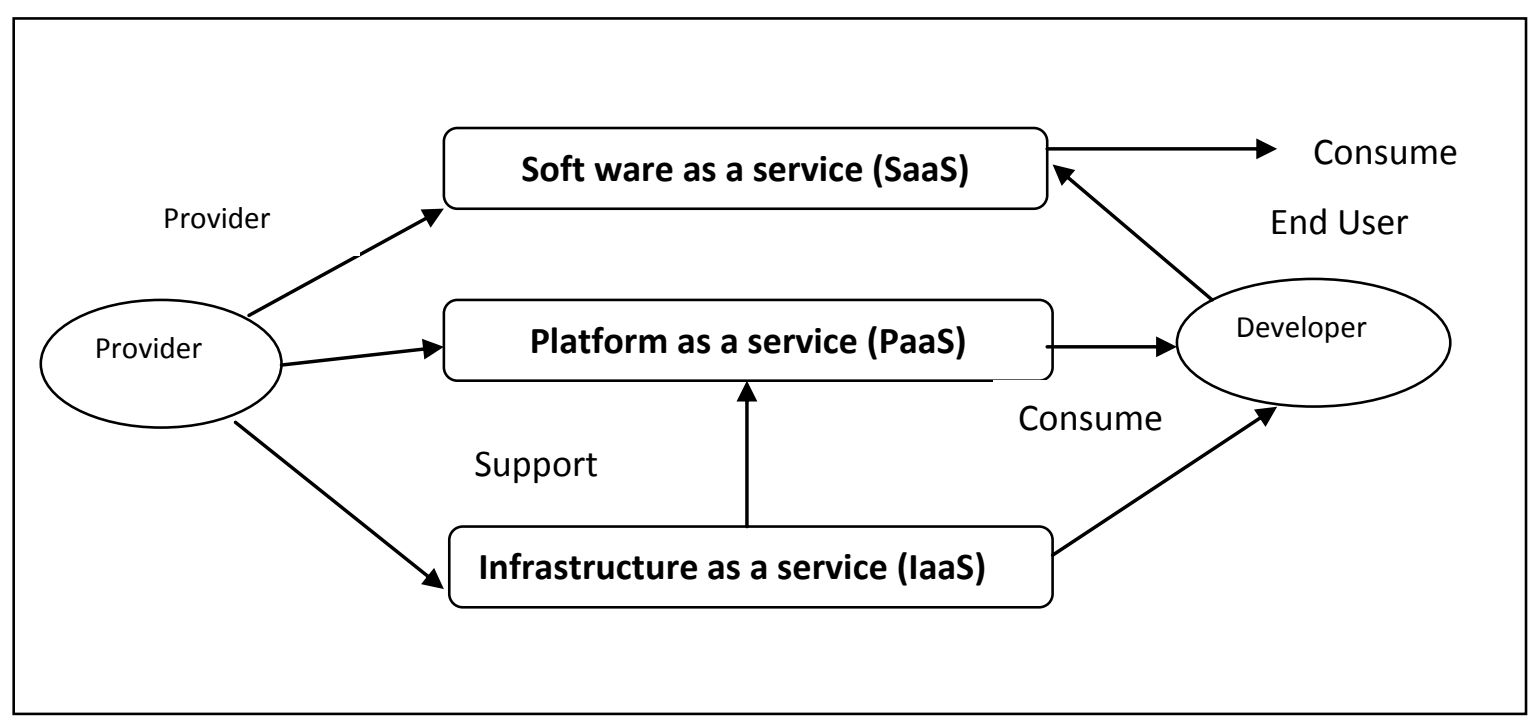

Figure 2: Roles in Cloud Computing

\section{TRUST IN THE CLOUD}

Trust and security have get to be significant to ensure the sound advancement of cloud stages giving answers for concerns, for example, the absence of protection and insurance, the assurance of security and creator rights, Security and security have been demonstrated to be two essential obstruction concerning the general appropriation of the distributed computing ideal model. With a specific end goal to tackle these issues in the laaS administration layer, a model of dependable distributed computing which gives a shut execution environment to the private execution of virtual machines was proposed. This work has indicated how the issue can be understood utilizing a Trusted Platform Module. The proposed model called 'Dusted Cloud Computing Platform (TCCP) should give larger amounts of unwavering quality, accessibility and security. In this arrangement, them is a group hub that goes about as a Thirsted Coordinator (TC). Dif (min hubs in the group must enlist with the TC so as to guarantee and confirm its key and estimation ion list. The TC keeps a rundown of ousted hubs. At the point when a virtual machine is begun or a movement happens, the TC confirms whether the hub is dependable so that the client of the virtual machine may make certain that the stage stays reliable. A key and a mark are utilized for distinguishing the hub. In the TCCP model, the private accreditation power is included in every exchange together with the TC. Shen et al. introduced a technique for building a dependable distributed computing environment by Incorporating a 'Rusted Computing Platform (TCP) to the distributed computing framework. The TCP is utilized to give confirmation, privacy and uprightness. This plan showed positive results for confirmation, standard based access and information security in the distributed computing environment.

\section{FILE SHARING IN CLOUD}

Cloud computing offers incredible adaptability for clients, because of the way that clients don't need to stress over administration intricacy identified with every framework, for instance, the databases can be exchanged to server farms of vast specific organizations, despite the (act that the administration information in outsourced situations aren't generally dependable. Clients are getting to be reliant on the accessibility and respectability offered by capacity administration suppliers. In this manner, it is important to utilize models of secure information stockpiling so as to guarantee the respectability of cloud client's information. One of the issues that distributed computing has the capacity fathom is the stockpiling of records and their dissemination with high rate of accessibility. There any a few ways to deal with oversee information in the cloud and every framework utilizes a particular way to deal with endure information. Among these methodologies, or can highlight new document frameworks, systems and recommendations for capacity and preparing inhumation

\subsection{Protected Distributed Data Storage in Cloud Computing}

One of the center administrations gave by cloud computing is information stockpiling. It postures new difficulties in making secure and dependable information stockpiling and access offices over remote administration suppliers in the cloud. The security of information stockpiling is one of the fundamental assignments to be dealt with before the venture for distributed computing is completely acknowledged. There are no less than two concerns when utilizing the cloud. One worry' is: clients would prefer not to uncover their information to the cloud administration supplier. Another concern is that clients are uncertain about the information trustworthiness thatthey get from the cloud. Consequently, inside of the cloud, more than routine security instruments will be needed for information security. One of the fundamental difficulties that keep away from end clients from receiving cloud administration stockpiling is the apprehension of losing information or infringement of it. Along these lines, the information uprightness and temperamental stockpiling is a noteworthy test for suppliers of distributed storage. It is fundamental to minimize the trepidation of clients, give innovations that capable client to confirm the trustworthiness of your information. Administration suppliers of cloud document stockpiling exhibited don't tackle issues identified with the dependable trade of documents between companions. The same concern is identified with the accessibility of records, taking care of this issue through record copy. Encryption methods can be utilized to guarantee information protection in the cloud. In any case these methods have huge execution ramifications of inquiries in SGI3Ds. In this way, options for coordinating encryption strategies with database administration frameworks ought to be assessed and proposed, since information encryption computational unpredictability expands the reaction time of the inquiry. Also, it is important 
to propose a model for a solid documents trade in the distributed computing environment, in light of the fact that this issue has not been explained.

\section{HIGH LEVEL TRUST MODEL FOR CONSISTENT FILE SHARING}

As per the audit and related examination, it is important to utilize a distributed computing trust model to guarantee the trading of documents among cloud clients in a reliable way. In this segment, we acquaint a trust model with set up a positioning of reliable hubs and empower the protected sharing of records among companions in a private cloud. The earth figuring private cloud was picked in light of the fact that we work with a particular setting of dispersing documents, where the records have a fancied conveyance and accessibility.

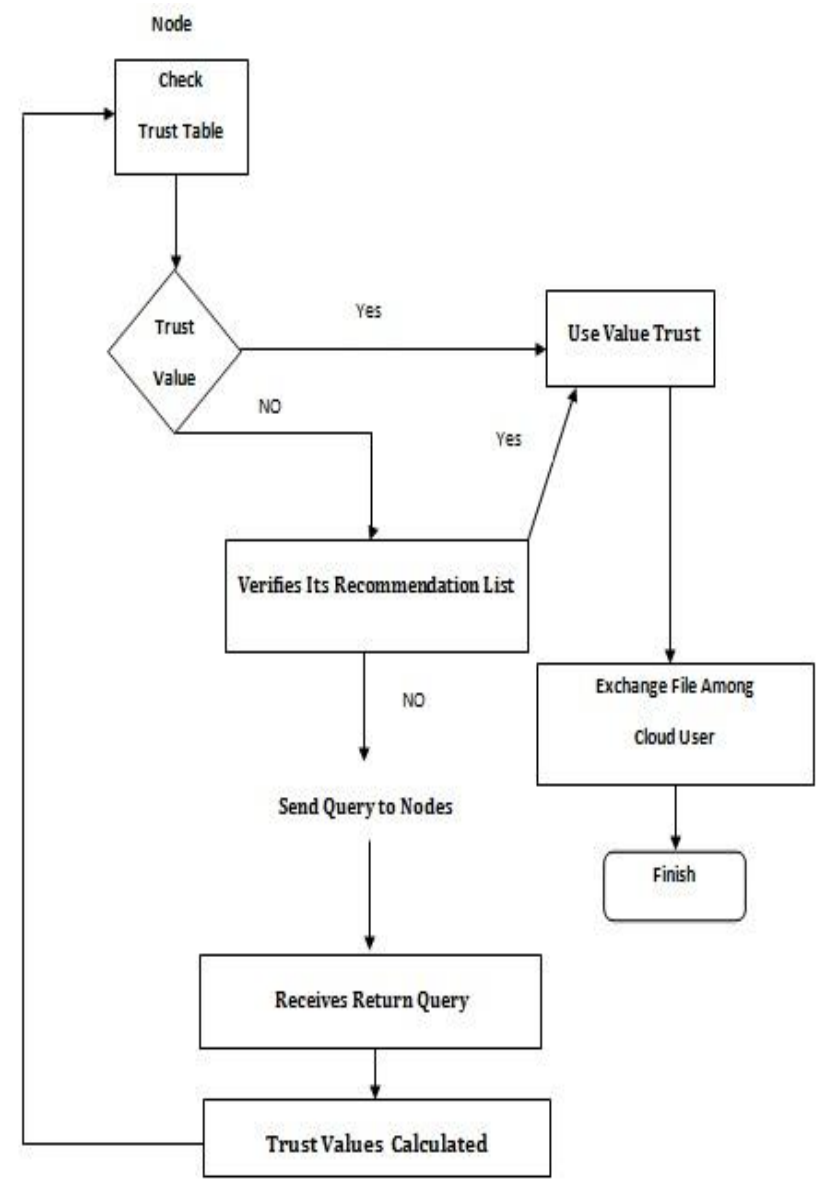

Figure3: High Level Trust Model

When all is said in done, trust of hub An in hub B, in the setting of a private cloud NP, can be spoken to by a quality V which measures the desire that a specific hub will have great conduct in the private cloud, so trust can be communicated by: The trust estimation of a hub demonstrates its air or suitability to perform the operations between companions of cloud. This worth is ascertained in view of the history collaborations/inquiries between the hubs, can to have quality going between $\{0,1\}$. By and large, the trust of hub An in hub $\mathrm{B}$, in the connection of a private cloud NP, can be spoken to by a quality $\mathrm{V}$ which measures the desire that a specific hub will act in the private cloud, so the trust can be communicated by:
$\mathrm{T} n \mathrm{p}(\mathrm{a}, \mathrm{h})=$ Vhnp

Represents the trust of An in B in the private cloud NP and V represents worth trust of $\mathrm{B}$, in the private cloud NP broke down by A. As indicated by meaning of trust, $\mathrm{V}$ is proportional to questions sent and got (cooperation) by an identified with B in cloud NP. As the cooperation's are made between the hubs of private cloud, the data is utilized for the computation of trust.

Hubs of a private cloud ought to have the capacity to think about whether as a trust worth is worthy, producing trust level. In the event that the hub surpasses the level inside of an arrangement of investigated qualities, it must have the capacity to judge the hub in a certain level of trust. Trust degree can change as indicated by a quantitative assessment: a hub has a high trust in another, a hub has low trust in another, a hub doesn't have adequate criteria to opine, a hub,and trusts enough to opine, and so on...

Table: 1Reference values for trust

\begin{tabular}{|l|l|l|}
\hline Volume & Description & Decision \\
\hline 0 & $\begin{array}{l}\text { No trust in nodes in the private } \\
\text { cloud }\end{array}$ & No Opinion \\
\hline$[0,0.39]$ & $\begin{array}{l}\text { Low trust in nodes in the } \\
\text { private cloud }\end{array}$ & NO Trust \\
\hline$[0.4,0.59]$ & $\begin{array}{l}\text { Average trust in nodes in the } \\
\text { private cloud }\end{array}$ & No Trust \\
\hline$[0.6,0.89]$ & $\begin{array}{l}\text { High trust in nodes in the } \\
\text { private cloud }\end{array}$ & Trust \\
\hline$[0.9,0.99]$ & $\begin{array}{l}\text { Very High trustin nodes in the } \\
\text { private cloud }\end{array}$ & Trust \\
\hline
\end{tabular}

As per data in the reference table, one hub trusts another hub from trust esteem $T_{-}$0.6. The trust qualities are computed from inquiries between the hubs of NP, permitting getting the essential data for last figuring of trust. The trust data is put away through the individual records of connection with the separate hub, staying in neighborhood database data about the conduct of every hub in the cloud that needs to trade a record (nearby Mist table and neighborhood suggestions table). The count oftrust a hub An in B in cloud NPwill be spoken to by:

$$
\mathrm{T} \mathrm{np}(\mathrm{a}, \mathrm{h})=\sum_{\boldsymbol{n} \boldsymbol{p}=\mathbf{1}}^{\mathbf{1}} \boldsymbol{V} \mathrm{hnb}(\mathrm{b}, \mathrm{m} 1)+(\mathrm{b}, \mathrm{m} 2)+(\mathrm{b}, \mathrm{m} 3)+\ldots(\mathrm{b}, \mathrm{mn}) \leq 1
$$

Pour viewpoints can to have effect on estimation of direct trust of a hub, as demonstrated in Table 3. More prominent stockpiling limit and handling limit have more weight in the decision of a hub more solid, in light of these elements are the in charge of guarantee the respectability and document stockpiling. To ascertain direct trust of a hub, it is credited by director of the private cloud: stockpiling limit and preparing with weights of $35 \% .15 \%$ to connection and the staying $15 \%$ to working framework. Realizing that a hub can to have the mist quality running from [.01] and that these qualities are variable over the long run, a hub can have its capacity limit expanded or diminished, it's important that mist mirrors the conduct of a hub in a given time of time. Hubs with consistent qualities ought to hence be more solid on the grounds that they have less variety in essential attributes. 
Table 2: Aspects Affecting the Trust Direct Node

\begin{tabular}{|l|l|l|l|l|}
\hline $\begin{array}{l}\text { Storage } \\
\text { capacity }\end{array}$ & $\begin{array}{l}\text { Process } \\
\text { ing } \\
\text { capacit } \\
\mathbf{y}\end{array}$ & $\begin{array}{l}\text { Link } \\
\text { capaci } \\
\text { ty }\end{array}$ & $\begin{array}{l}\text { Operati } \\
\text { ngstem }\end{array}$ & $\begin{array}{l}\text { Trust } \\
\text { Direct }\end{array}$ \\
\hline High & High & High & High & High \\
\hline High & High & Low & Low & High \\
\hline High & Low & High & Low & $\begin{array}{l}\text { Average (it depend on } \\
\text { the values storage and } \\
\text { processing) }\end{array}$ \\
\hline High & Low & Low & Low & Low \\
\hline Low & High & High & Low & $\begin{array}{l}\text { Average (it depend on } \\
\text { the values storage and } \\
\text { processing) }\end{array}$ \\
\hline Low & High & Low & Low & Low \\
\hline Low & Low & High & Low & Low \\
\hline Low & Low & Low & Low & Low \\
\hline
\end{tabular}

$\operatorname{Tnp}(\mathrm{a}, \mathrm{h})=\sum_{\boldsymbol{n} \boldsymbol{p}=\mathbf{1}}^{\mathbf{1}} \boldsymbol{V} \mathrm{hnb}((\mathrm{b}, \mathrm{m} 1) * 0.35)+((\mathrm{b}, \mathrm{m} 2) * 0.35)+((\mathrm{b}, \mathrm{m} 3$ )$* 0.15)+\ldots((\mathrm{b}, \mathrm{mn}) * 0.15) \leq 1$

\subsection{Preliminary Results and Simulations}

Once allocated the weights measurements, can perform the figuring of the trust of a hub. Vis. Consider the hub An and B and between them execute 10 emphases (i). The reproduction is $\mathrm{ft}$ : begun by performing the computation with the hub A trusting $\mathrm{B}$, is allocated the quality 1 to all measurements.

Table 3: Simulation Calculation of Trust

\begin{tabular}{|c|c|c|c|c|c|c|}
\hline \multicolumn{7}{|c|}{ Iteration } \\
\hline $\begin{array}{l}\mathrm{CP} \\
(35 \%)\end{array}$ & $\begin{array}{l}\text { CA } \\
(35 \%)\end{array}$ & $\begin{array}{l}\text { CE } \\
(15 \%)\end{array}$ & $\begin{array}{l}\text { SO } \\
(15 \%)\end{array}$ & $\mathrm{CD}$ & $\begin{array}{l}\text { CD } \\
\text { Final }\end{array}$ & $\begin{array}{l}\text { Decision } \\
\text { Trust }\end{array}$ \\
\hline 1 & 1 & 1 & 1 & 1 & 1 & Trust \\
\hline \multicolumn{7}{|c|}{ Iteration2 } \\
\hline $\begin{array}{l}\text { CP } \\
(35 \%)\end{array}$ & $\begin{array}{l}\text { CA } \\
(35 \%)\end{array}$ & $\begin{array}{l}\text { CE } \\
(15 \%)\end{array}$ & $\begin{array}{l}\mathrm{SO} \\
(15 \%)\end{array}$ & $\mathrm{CD}$ & $\begin{array}{l}\text { CD } \\
\text { Final }\end{array}$ & $\begin{array}{l}\text { Decision } \\
\text { Trust }\end{array}$ \\
\hline 0.01 & 0.82 & 0.51 & 0.91 & 0.51 & 0.75 & Trust \\
\hline \multicolumn{7}{|c|}{ Iteration3 } \\
\hline $\begin{array}{l}\text { CP } \\
(35 \%)\end{array}$ & $\begin{array}{l}\text { CA } \\
(35 \%)\end{array}$ & $\begin{array}{l}\mathrm{CE} \\
(15 \%)\end{array}$ & $\begin{array}{l}\mathrm{SO} \\
(15 \%)\end{array}$ & $\mathrm{CD}$ & $\begin{array}{l}\text { CD } \\
\text { Final }\end{array}$ & $\begin{array}{l}\text { Decision } \\
\text { Trust }\end{array}$ \\
\hline 0.30 & 0.08 & 0.62 & 0.89 & 0.35 & 0.63 & Trust \\
\hline \multicolumn{7}{|c|}{ Iteration 4} \\
\hline $\begin{array}{l}\mathrm{CP} \\
(35 \%)\end{array}$ & $\begin{array}{l}\text { CA } \\
(35 \%)\end{array}$ & $\begin{array}{l}\mathrm{CE} \\
(15 \%)\end{array}$ & $\begin{array}{l}\text { SO } \\
(15 \%)\end{array}$ & $\mathrm{CD}$ & $\begin{array}{l}\mathrm{CD} \\
\text { Final }\end{array}$ & $\begin{array}{l}\text { Decision } \\
\text { Trust }\end{array}$ \\
\hline 0.76 & 0.95 & 0.85 & 0.14 & 0.58 & 0.62 & Trust \\
\hline \multicolumn{7}{|c|}{ Iteration5 } \\
\hline $\begin{array}{l}\text { CP } \\
(35 \%)\end{array}$ & $\begin{array}{l}\text { CA } \\
(35 \%)\end{array}$ & $\begin{array}{l}\mathrm{CE} \\
(15 \%)\end{array}$ & $\begin{array}{l}\text { SO } \\
(15 \%)\end{array}$ & $\mathrm{CD}$ & $\begin{array}{l}\text { CD } \\
\text { Final }\end{array}$ & $\begin{array}{l}\text { Decision } \\
\text { Trust }\end{array}$ \\
\hline 0.06 & 0.11 & 0.30 & 0.76 & 0.22 & 0.54 & $\begin{array}{l}\text { Not } \\
\text { Trust }\end{array}$ \\
\hline & & & & & & \\
\hline
\end{tabular}

\begin{tabular}{|c|c|c|c|c|c|c|}
\hline $\begin{array}{l}\text { CP } \\
(35 \%)\end{array}$ & $\begin{array}{l}\text { CA } \\
(35 \%)\end{array}$ & $\begin{array}{l}\mathrm{CE} \\
(15 \%)\end{array}$ & $\begin{array}{l}\text { SO } \\
(15 \%)\end{array}$ & $\mathrm{CD}$ & $\begin{array}{l}\text { CD } \\
\text { Final }\end{array}$ & $\begin{array}{l}\text { Decision } \\
\text { Trust }\end{array}$ \\
\hline 0.58 & 0.01 & 0.50 & 0.89 & 0.15 & 0.52 & $\begin{array}{l}\text { Not } \\
\text { Trust }\end{array}$ \\
\hline \multicolumn{7}{|c|}{ Iteration7 } \\
\hline $\begin{array}{l}\text { CP } \\
(35 \%)\end{array}$ & $\begin{array}{l}\text { CA } \\
(35 \%)\end{array}$ & $\begin{array}{l}\text { CE } \\
(15 \%)\end{array}$ & $\begin{array}{l}\mathrm{SO} \\
(15 \%)\end{array}$ & $\mathrm{CD}$ & $\begin{array}{l}\text { CD } \\
\text { Final }\end{array}$ & $\begin{array}{l}\text { Decision } \\
\text { Trust }\end{array}$ \\
\hline 0.15 & 0.33 & 0.16 & 0.48 & 0.76 & 0.40 & $\begin{array}{l}\text { Not } \\
\text { Trust }\end{array}$ \\
\hline \multicolumn{7}{|c|}{ Iteration8 } \\
\hline $\begin{array}{l}\text { CP } \\
(35 \%)\end{array}$ & $\begin{array}{l}\text { CA } \\
(35 \%)\end{array}$ & $\begin{array}{l}\mathrm{CE} \\
(15 \%)\end{array}$ & $\begin{array}{l}\text { SO } \\
(15 \%)\end{array}$ & $\mathrm{CD}$ & $\begin{array}{l}\text { CD } \\
\text { Final }\end{array}$ & $\begin{array}{l}\text { Decision } \\
\text { Trust }\end{array}$ \\
\hline 0.70 & 0.34 & 0.61 & 0.79 & 0.57 & 0.50 & $\begin{array}{l}\text { Not } \\
\text { Trust }\end{array}$ \\
\hline \multicolumn{7}{|c|}{ Iteration9 } \\
\hline $\begin{array}{l}\text { CP } \\
(35 \%)\end{array}$ & $\begin{array}{l}\text { CA } \\
(35 \%)\end{array}$ & $\begin{array}{l}\mathrm{CE} \\
(15 \%)\end{array}$ & $\begin{array}{l}\text { SO } \\
(15 \%)\end{array}$ & $\mathrm{CD}$ & $\begin{array}{l}\text { CD } \\
\text { Final }\end{array}$ & $\begin{array}{l}\text { Decision } \\
\text { Trust }\end{array}$ \\
\hline 0.25 & 0.95 & 0.53 & 0.89 & 0.53 & 0.51 & $\begin{array}{l}\text { Not } \\
\text { Trust }\end{array}$ \\
\hline \multicolumn{7}{|c|}{ Iteration10 } \\
\hline $\begin{array}{l}\text { CP } \\
(35 \%)\end{array}$ & $\begin{array}{l}\text { CA } \\
(35 \%)\end{array}$ & $\begin{array}{l}\mathrm{CE} \\
(15 \%)\end{array}$ & $\begin{array}{l}\text { SO } \\
(15 \%)\end{array}$ & $\mathrm{CD}$ & $\begin{array}{l}\text { CD } \\
\text { Final }\end{array}$ & $\begin{array}{l}\text { Decision } \\
\text { Trust }\end{array}$ \\
\hline 0.58 & 0.80 & 0.72 & 0.64 & 0.69 & 0.53 & $\begin{array}{l}\text { Not } \\
\text { Trust }\end{array}$ \\
\hline \multicolumn{7}{|c|}{ Iteration11 } \\
\hline $\begin{array}{l}\text { CP } \\
(35 \%)\end{array}$ & $\begin{array}{l}\text { CA } \\
(35 \%)\end{array}$ & $\begin{array}{l}\mathrm{CE} \\
(15 \%)\end{array}$ & $\begin{array}{l}\text { SO } \\
(15 \%)\end{array}$ & $\mathrm{CD}$ & $\begin{array}{l}\text { CD } \\
\text { Final }\end{array}$ & $\begin{array}{l}\text { Decision } \\
\text { Trust }\end{array}$ \\
\hline 0.27 & 0.54 & 0.95 & 0.19 & 0.46 & 0.52 & $\begin{array}{l}\text { Not } \\
\text { Trust }\end{array}$ \\
\hline
\end{tabular}

\section{COMPARISONS WITH OTHER TRUST MODELS}

There are a few algorithms which have been proposed for notoriety based trust administration in various frameworks. In this area, we should to analyze the distinctions among them. As one of the most punctual works around there, the calculation planned by Aberer and Despotovic is to recognize unscrupulous associates by a protest based framework.

Table 4,5 beneath demonstrate two correlations of five trust models specified above, from base and degree sides. Aside from the above correlations, there are a few detriments of them ought to be given careful consideration. It is difficult to recognize standardized trust values in EIGNTRUST Model. The trust demonstrates in substantial scale, a great deal more work is required for processing trust values. In the notoriety based trust model, just halfway trickery can be counteracted. 
Table4: comparison of base in some trust models

\begin{tabular}{|l|l|}
\hline Items & Base \\
\hline Global Trust Model & Binary trust \\
\hline NICE Model & Cookie \\
\hline IUGEN Trust Model & Trust value \\
\hline Trust in large-scale & A set of acquaintances \\
\hline A reputation - based trust & $\begin{array}{l}\text { Qualify and access the trust } \\
\text { worth }\end{array}$ \\
\hline
\end{tabular}

Table5: comparison of scope in some trust models

\begin{tabular}{|l|l|}
\hline Items & Scope \\
\hline Global Trust Model & As a part of any model \\
\hline NICE Model & Guard against malicious peers \\
\hline IUGEN Trust Model & $\begin{array}{l}\text { Reputation is assigned by } \\
\text { each other }\end{array}$ \\
\hline Trust in large-scale & Large scale \\
\hline A reputation - based trust & Ecommerce \\
\hline
\end{tabular}

\section{CONCLUSION}

Cloud computing has been center of a few late research, which exhibits the significance and need of trust model that guarantees solid and secure trade records. We have exhibited an outline of the distributed computing ideal model, and also its fundamental elements, architectures and organization models. Also, we recognized the principle issues identified with trust, protection and security in distributed computing situations. Keeping in mind the end goal to address these issues, we proposed a Rust model to guarantee solid trade of documents among clients in a private cloud environment, utilizing the ideas of trust and notoriety that has been promissory because of ID of issues and vulnerabilities identified with security, protection and trust that a, distributed computing environment presents. In our model, the trust estimation of a given hub is acquired from a pool of basic parameters identified with its suitability for performing stockpiling operations. Hubs with more noteworthy trust qualities are accordingly decided for further record stockpiling operations. As future work, we plan to actualize the proposed trust display and break down hub conduct after the positioning of dependable hubs is set up.

\section{REFERENCES}

[1] Minqi Thou, Rong Zhang, Dadan Zeng, and Veining Qian, "Serkikin the cloud computing 11'. era: a survey." Software Engineering Institute. Universal Communication. Symposium (IUCS), 4th International. IEEE Shanghai. pp. 40-46. China. 9784-4244-7821-7 (2010).

[2]Xue ling and Zhang lian.jun, "A Brief Survey on the Security Model of Cloud Corn \ 2010 Ninth International Symposium on Disaibuted Computing and Applications to- Engineering and Science (DCA BES). Hong Kong IEEE. pp. 475- 478. Aug 2010. 111

[3] P. Melt and T. Grance, "Draft nist working definition of cloud computing - v15," 21. Aug 7 'Elli. 2009. "

[4] T. Dillon, Chen Wu, and E. Chang, "Cloud Computing: Issues and Challenges," 24th IEEE International
Conference on Advanced Information Networking and Applications (AINA), pp. 27-13. Australia, 2010. ,eksiv

[5] Xian-Yong Li, Li-Tao Zhou. Yong Shl, and MI Guo. Trusted Computing Environment J, Model in Cloud Architecture," Proceedings of the Ninth International Conference on Machine/8.1 Learning and Cybernetics, 978•1-4244-6526-2. Qingdao. pp. 11-14. China. July 2010.

[6] A. Marinos and G. Briscoe, "Community cloud computing." in First International Conference Cloud Computing. CloudC.om, volume 5931 of Lecture Notes in Computer Science. pp. 472- ,-, 484. Springer (2009).

[7] HTakabi. 1 B. D. Joshi, and G. Ahn, "SecurityaitntiMeytelallenges in $\mathrm{Cl}$.6.1 Enviriannien, ts," IEEE Security d Privacy, vol. 8, no 6,.pp...24-31, Noik/Dec. 2010, /1/2" 1-00819.1109/MSP.2010.186.

[8] Masted Computing Platform," Intelligent Computation Technology and Automation (ICICTA), IEEE International Conference on Volume: 1, pp. 942-945. China. 2010.

[9] lluan-Chung Li, Po.11uei Ilan\& 1 iann-M in Yang, and Shiang-Jiun Chen, "Analysts $\backslash<\left(4\right.$, , $^{\prime} 410$._ $_{-}$cloud- Based Security Vulnerability Assessment," 2010 IEEE 7th International Con Clilusinas Engineering (ICEBE), pp. 490.494, 2010.

[10] C Popovic and Z. Ilocenski, "Cloud computing security issues andchallenges," M1PRO, 2010 Proceedings of the 33rd International Convention, pp. 344-349. 24.28 May 2010

URL: hup:theeexploreleeenrg/stampistamp.jsp?tp=\&arnumber $=$ Scrt317\&isournbern5533310.

[11] S. Uppoor, M. Flourlk-and A. Bilas, "Cloud-based synchronization of distributed file system International Conference, pp. 1-4. 2010. WORKSHOP, hierarchies," Cluster Computing Workshops and Posters (CLUSTER ')

[12] Qintaong Wei, Bharadwaj Veeravalli. Bozhao Gong. Lineang Zeng• and Dan Fen,, "C.DRM: A Cost-Effective Dynamic Replication Management Stheme for Cloud Storage Cluster," 2009 IEEE International Conference on Cluster Computing (CLUSTER), pp. 188-196, 2010.

[13] S. P. Marsh,"Fommlising Trust as a Computational Concept", Ph.D. Thesis, University of Stirling, 1994.

[14] T. Beth, M. Borcherding, and B. Klein, "Valuation of oust in open networks," In ESORICS 94. Brighton, UK, November 1994

[15] A. Josang and R. Ismail, "The Beta Reputation System," In Proceedings of the 15th Bled Electronic Commerce Conference, pp. 17-19. June 2002.

[16] A. Abdul-Rahman and S. Hallos, "A distributed trust model," In Proceedings of the 1997 New Security Paradigms Workshop, pp. 48-60, 1998.

[17] Zhidong Shen, Li Li, Fei Yan, and Xiaoping Wu, "Cloud Computing System Based on Trusted Computing Pladorm." Intelligent Computation Technology and Automation (1CICTA), IEEE International Conference on Volume: I, pp. 942-945. China. 2010. 